\title{
Mechanical performance of oil palm/kenaf fiberreinforced epoxy-based bilayer hybrid composites
}

\begin{abstract}
Owing to the recent trend and increasing awareness toward sustainable product design, natural fiber-based materials are gaining a revival popularity to replace synthetic fiber in the composites industries, especially for automotive structural and semi-structural applications. In this work, natural fibers bilayer hybrid composites were fabricated by hand-lay-up technique by reinforcing oil palm empty fruit bunch (EFB) and kenaf fiber mats with epoxy matrix. Experiments were carried out to study the effect of hybridizing of oil palm EFB-reinforced kenaf fiber on mechanical properties. Bilayer hybrid composites were prepared by hybridizing oil palm EFB and kenaf fiber by maintaining different weight ratios of oil palm EFB and kenaf fiber at $4: 1,1: 1$, and 1:4, with total fiber loading at $50 \%$ by weight. Results showed that the tensile and flexural properties improved substantially on increasing the content of kenaf fiber to oil palm EFB composites, whereas the impact properties of pure EFB composite was much higher than those of hybrid composites. The fracture surface morphology of tensile samples of the composites was determined using scanning electron microscopy (SEM).
\end{abstract}

Keyword: Oil palm fiber; Kenaf fiber; Epoxy; Hybrid composites; Mechanical properties; Morphological properties 